\title{
Investigation of three strategies for an international genetic evaluation of beef cattle weaning weight
}

\author{
Florence PHOCAS ${ }^{\mathrm{a}, \mathrm{b} *}$, Kath DONOGHUE ${ }^{\mathrm{b}}$, Hans Ulrich GRASER ${ }^{\mathrm{b}}$ \\ ${ }^{\text {a }}$ Station de génétique quantitative et appliquée, Institut national de la recherche agronomique, \\ 78352 Jouy-en-Josas Cedex, France \\ ${ }^{\mathrm{b}}$ Animal Genetics and Breeding Unit, University of New England, \\ NSW 2350 Armidale, Australia
}

(Received 24 November 2004; accepted 10 February 2005)

\begin{abstract}
Weaning weights from 83389 Limousin calves born between 1993 and 2002 in France and the Trans-Tasman block (Australia / New Zealand) were analysed to compare different strategies for running an international genetic evaluation for the breed. These records were a subset of the complete data for both countries and comprised a sample of herds that had recorded progeny of sires used across both countries. Genetic and phenotypic parameters for weaning weight were estimated within the countries. The estimates of direct genetic heritabilities were higher in France than in the Trans-Tasman block $(0.31$ vs. 0.22), while direct-maternal genetic correlations were less negative in the Trans-Tasman block $(-0.10)$ than in France $(-0.21)$. Different strategies for an international evaluation were studied, and the correlations between the estimated breeding values (EBV) of national evaluations and these strategies were derived. The international evaluation strategies were a) an animal model on raw performance data with non unity genetic correlations and heterogeneous residual and genetic variances across countries; b) the same animal model applied to pre-corrected (for fixed effects) performance data; and c) a sire model on de-regressed proofs (MACE). Estimates of the genetic correlations between weaning weight in both countries were $0.86(0.80)$ for direct (maternal) genetic effects for the first strategy. Estimation of variance components by MACE appeared to be very sensitive to the sample of bulls and their reliability approximations. Variance component estimates obtained using pre-corrected data were inconsistent with estimates on raw data. However, the EBV predicted using pre-corrected data and parameters estimated from the raw data were similar to those predicted from raw data. Correlations between national and international EBV were always high $(>0.90)$ for sires, whichever genetic effect (direct or maternal) or international evaluation model was considered. The ranking of the bulls in the top 100 is of primary interest in terms of international genetic evaluation. In this study, some re-ranking of sires was observed for the top 100 bulls between countries and between the three international evaluation models. Thus, the origin of top sires may vary according to the implemented international evaluation strategy.
\end{abstract}

limousin cattle / animal model / MACE / genetic parameters

\footnotetext{
*Corresponding author: phocas@dga.jouy.inra.fr
} 


\section{INTRODUCTION}

The Limousin breed has been developing in several countries for the last four decades, but the genetic evaluation of seed stock is usually performed within country. Increasingly, breeders are seeking to compare domestic and foreign seed stock in order to enlarge the choice of animals that best fit their own selection objectives. Some populations in different countries are currently simultaneously evaluated: for example, animals from France, Italy, Luxembourg and Hungary; Australian and New Zealand animals; US and Canadian animals. These evaluations are across country analyses that assume single trait and homogeneous variances across countries. There are several technical issues to consider when implementing an across country genetic evaluation, along with important political considerations. Firstly, connectedness needs to be sufficient across countries in order to estimate genetic correlations and to compare estimated breeding values (EBV). Secondly, an international genetic evaluation model has to be defined and implemented. In 1981, the International Dairy Federation [8] recommended for international genetic evaluations in dairy cattle, the use of conversion formulas between two countries that transform EBV from the exporting country into the base and scale of EBV of the importing country [7,13,27]. In the nineteen-nineties, multiple-trait across country evaluation (MACE) [23] became the standard for international comparison of dairy bulls. The dependent variable chosen for dairy MACE was de-regressed proofs [1] and variability in reliability of national EBV was accommodated in the variance structure of the residuals in MACE by different weighting factors [5]. To allow for international evaluation of all animals, a global animal model has been proposed [26] for dairy cattle. Although this alternative is scientifically appealing, it has technical and political limitations that limit its usefulness in dairy international evaluations. These include the huge number of countries and raw records in the main dairy cattle breeds, as well as the fact that a global animal model would lead to national genetic evaluations becoming redundant. Moreover, there are a lot of different statistical models applied for the same trait across the world (sire model or animal model, linear or random regression test day model...) and getting agreement across countries for a unique model may be impossible. Consequently, an alternative procedure applying an animal model on pre-corrected records from each country has been proposed recently as a way to preserve the knowledge and data quality control at the national level [2]. International genetic evaluation in beef cattle has only recently gained the attention of researchers, and has tended towards promoting an animal model on raw performance records, and assuming a single trait model across countries [3,11,15]. A first attempt at 
international beef evaluation allowing different traits across countries was undertaken for Charolais cattle across Ireland, France and the United Kingdom [20]. Research is also currently being undertaken regarding the implementation of an international genetic evaluation of growth traits for the Hereford breed in Australia, North and South America.

The aims of this study were to estimate genetic parameters for Limousin weaning weight across France and Australia / New Zealand, and to investigate the benefit of using a complex model, which treats raw data in each country as a correlated trait, versus a simpler model on pre-corrected records or deregressed EBV.

\section{MATERIALS AND METHODS}

\subsection{Limousin weaning weight records}

\subsubsection{Initial population data}

A total of 1175152 and 38011 adjusted weaning weights (WW) recorded in France and Australia / New Zealand, respectively, were initially provided for the study (Tab. I). These records are the total purebred records used in the national evaluations of both countries: IBOVAL for French (Fr) evaluation and BREEDPLAN for Trans-Tasman (Tr) evaluation. French performance data spanned the years 1971-2002 and 6242 herds, while Trans-Tasman data records were from 1976-2002 and 347 herds. Weaning weight was adjusted to 200 days in Trans-Tasman data and 210 days in French data.

There were 31399 and 2395 French and Trans-Tasman sires represented in the respective populations. Consequently, there were many more progeny WW records per sire in the French population (37) in comparison to the Trans-Tasman population (16). There was heavy use of French bulls in the Trans-Tasman population, with 263 of the 347 herds having trait records for calves sired by either a French sire or a French maternal grandsire. There were 71 bulls born in France identified as sires of calves recorded in BREEDPLAN, with 66 of these also maternal grandsires (MGS). However, relatively few of these French bulls also had recorded progeny in France. Thus, the direct connections between the two countries (established through sires having progeny in both countries) were not numerous: they consisted of 16 sires born between 1988 and 1994 (Tab. II). These bulls accounted for only 4\% of the total number of records, although some sired a large number of progeny. These 16 link sires were all MGS in France and 12 were MGS in both countries. In addition to direct links, indirect connections could be found in the pedigree of 20 French 
Table I. Age adjusted weaning weight statistics.

\begin{tabular}{lrccc}
\hline & Number & $\begin{array}{c}\text { Adjustment } \\
\text { age (days) }\end{array}$ & $\begin{array}{c}\text { Mean } \\
(\mathrm{kg})\end{array}$ & $\begin{array}{c}\text { SD } \\
(\mathrm{kg})\end{array}$ \\
\hline France & 1175152 & 210 & 247.2 & 43.0 \\
AUS / NZ & 38011 & 200 & 232.3 & 40.8 \\
\hline
\end{tabular}

Table II. Number of (grand)progeny of link sires across France and Australia / New Zealand spread across all herds (in brackets: spread across herds sampled for the study).

\begin{tabular}{lcccc}
\hline French ID & \multicolumn{2}{c}{ Progeny } & \multicolumn{2}{c}{ Grandprogeny } \\
\hline & AUS / NZ & France & AUS / NZ & France \\
\hline FR1988004715 & $114(93)$ & $21061(2495)$ & $17(10)$ & $9202(1351)$ \\
FR8791002491 & $97(88)$ & $4803(787)$ & $30(24)$ & $1452(292)$ \\
FR8791051813 & $61(60)$ & $104(19)$ & $13(13)$ & $31(7)$ \\
FR8792004759 & $56(49)$ & $122(44)$ & $2(0)$ & $2(0)$ \\
FR8793007496 & $47(46)$ & $108(90)$ & $15(15)$ & $82(55)$ \\
FR8791002604 & $36(25)$ & $374(147)$ & $7(5)$ & $70(31)$ \\
FR1992000066 & $29(24)$ & $196(82)$ & $9(6)$ & $98(68)$ \\
FR3693000206 & $25(22)$ & $1227(204)$ & $0(0)$ & $12(0)$ \\
FR1692111209 & $23(20)$ & $13058(1537)$ & $1(0)$ & $611(93)$ \\
FR1991000217 & $20(14)$ & $1338(532)$ & $5(5)$ & $742(291)$ \\
FR8790014838 & $15(14)$ & $3806(557)$ & $0(0)$ & $515(91)$ \\
FR2392021153 & $13(11)$ & $8(0)$ & $6(6)$ & $4(0)$ \\
FR1992014267 & $11(6)$ & $887(175)$ & $6(4)$ & $0(0)$ \\
FR2394011796 & $7(7)$ & $2824(421)$ & $0(0)$ & $7(0)$ \\
FR8790011897 & $4(0)$ & $9(0)$ & $3(0)$ & $5(0)$ \\
FR1992002007 & $3(0)$ & $367(171)$ & $0(0)$ & $7(0)$ \\
\hline
\end{tabular}

bulls used as sires and MGS in Australia / New Zealand only, and present in the French pedigree files. Due to the weakness of genetic ties across countries, the estimation procedure of genetic parameters may converge with difficulty and standard errors may be very large due to the flatness of the likelihood curve.

\subsubsection{Population sampling}

Table III gives a summary of the dataset used in the present analysis. Records before 1993 were discarded, since very little information was present before that time to connect the French and the Trans-Tasman populations. A Sire-MGS model was applied to the same sampled herds over a 20 -year period from 1983-2002 (unpublished results) in order to show that this time edit 
Table III. Summary of the sampled dataset.

\begin{tabular}{lcc}
\hline Number & France & AUS / NZ \\
\hline Average weaning weight $(\mathrm{kg})$ & 261.4 & 238.7 \\
Record & 65543 & 17846 \\
Herd & 203 & 165 \\
Contemporary group & 8708 & 3743 \\
Dam & 22470 & 7821 \\
Sire & 1571 & 844 \\
Maternal Grand Sire & 1627 & 800 \\
Link progeny & 7261 & 468 \\
\hline
\end{tabular}

did not provoke any change in the estimated genetic parameters within and across countries. The 10-year period 1993-2002 corresponded to the period of birth for $99 \%$ of the Trans-Tasman calves sired by the link bulls. In order to restrict the size of the final dataset, several edits were undertaken. These included the elimination of single record contemporary groups from TransTasman data and those with less than three records in French data. A minimum of 5 and 10 calves per sire or MGS was required in Australia / New Zealand and France, respectively, as well. The edits were different between French and Trans-Tasman populations because of differences in population size and structure across countries. More severe edits in the Trans-Tasman population would have removed too many genetic links with the French population. Less edits in the French population would have been computationally demanding and worthless either to improve genetic links or to get a better estimate of genetic parameters: both aspects were studied under a Sire-MGS model (unpublished results) in order to determine the levels of edits for each country.

Sampling of French herds was undertaken due to their large number in comparison with the number of Trans-Tasman herds. It was computationally impossible to estimate genetic parameters for all French herds. Half of the link sires had many progeny ( $>500$ per sire) spread across 2275 French herds, while the remaining sires had relatively few progeny and in only a few herds. Thus, the herds were retained for analysis if they had progeny of link sires with lower numbers of progeny, as well as at least 200 records over the last 20 years. By sampling French herds this way, sufficient progeny numbers for the highly used link sires were obtained and also kept all the information available for the link sires that were less spread across herds (Tab. II). Herds with link sires were probably better managed herds and/or had better genetic levels because their average WW (Tab. III) was $12 \mathrm{~kg}$ above the average WW of all herds recorded within the same period. Consequently, some selection bias may be 
feared and estimates of genetic parameters within France may be biased in the sampled dataset. However this bias would probably be very moderate because $12 \mathrm{~kg}$ is only $30 \%$ of WW standard deviation and the estimates of genetic parameters will be compared in Section 3.1.1. to those of other studies in order to evaluate the risk of selection bias. In the Trans-Tasman dataset, herds with less than 20 records over the last 20 years and without any WW for calves sired by either a French sire or MGS were removed from the analysis; only 49 of the 165 remaining herds had progeny of the link sires.

Thus, after the edits, only 13 bulls directly connected the two countries in the sampled datasets, since the three link sires with less than 10 records in each country were removed. Only 7 of these 13 bulls were common MGS across countries in the sampled datasets (Tab. II).

\subsection{Alternative models}

An across-country evaluation using an animal model that assumed WW was a different trait in each country was compared with two simpler strategies for international evaluation of beef cattle, as well as with within-country (national) genetic evaluations. An essential criterion to determine the best international model was the consistency between national and international ranking of animals, at least within populations of animals with records in a single country. EBVs preliminary results [18] indicated that considering WW as the same trait across countries (i.e. applying a single-trait animal model) is not a satisfactory strategy when direct-maternal correlations are not close to zero within and across countries. This was the case even after accounting for heterogeneous environmental and genetic variances across countries, and when direct and maternal genetic correlations across countries were close to unity. Therefore, all across-country genetic evaluation models presented in this paper assumed that WW was a different trait across countries. Under this approach, countryspecific estimated breeding value (EBV) distributions were generated, in comparison to a common ranking of animals across countries that would have been performed if a single-trait across-country evaluation model had been used.

\subsubsection{Within-country evaluation model (AMWC model)}

An animal model with maternal effects was run separately on the French data subset (performance vector $\mathbf{y}_{\mathbf{1}}$ ) and the Trans-Tasman data subset (performance vector $\mathbf{y}_{2}$ ). The AMWC model included fixed effects (b: contemporary 
group, birth month and age of dam), direct $\left(\mathbf{u}_{\mathbf{d}}\right)$ and maternal $\left(\mathbf{u}_{\mathbf{m}}\right)$ genetic effects, maternal permanent environment effects $\left(\mathbf{e}_{\mathbf{m}}\right)$ and residual error $(\mathbf{e})$ :

$$
\mathbf{y}_{\mathbf{i}}=\mathbf{X b}+\mathbf{Z}_{\mathbf{d}} \mathbf{u}_{\mathbf{d}}+\mathbf{Z}_{\mathbf{m}} \mathbf{u}_{\mathbf{m}}+\mathbf{W}_{\mathbf{m}} \mathbf{e}_{\mathbf{m}}+\mathbf{e} .
$$

The second moments of the random effects, $\operatorname{var}\left[\begin{array}{l}\mathbf{u}_{\mathbf{d}} \\ \mathbf{u}_{\mathbf{m}}\end{array}\right]=\mathbf{G}_{\mathbf{0}} \otimes \mathbf{A}$, with $\mathbf{G}_{\mathbf{0}}=\left[\begin{array}{ll}\sigma_{\mathrm{d}}^{2} & \sigma_{\mathrm{dm}} \\ \sigma_{\mathrm{dm}} & \sigma_{\mathrm{m}}^{2}\end{array}\right]$, and $\operatorname{var}\left[\mathbf{e}_{\mathbf{m}}\right]=\mathbf{I} \cdot \sigma_{e m}^{2}$ and $\operatorname{var}[\mathbf{e}]=\mathbf{I} \cdot \sigma_{e}^{2}$ were REML estimates with ASREML [6].

In both countries, the contemporary group (CG) was defined as a "herdyear-season-management group-sex of the calf" combination. The CG definition used in real French national evaluation does not account for sex or birth season of the calf. However, considering these two effects only as average effects across years and herds gave biased EBV due to significant sire by sex and sire by season interactions (unpublished results). Consequently, the season effect defined within French CG was a 2 month-period starting by grouping January and February together and so on. An overall birth month effect was also fitted for the French data. In Australia / New Zealand, the season effect was a 2-month period starting at the first calving date within herd-year. Although Trans-Tasman WW were already pre-corrected for age of dam, this effect was fitted for both countries because some extra variation due to age of the dam remained in the data. Age of the dam was classified into 11 classes according to significantly different LS mean estimates in the French data: < 28 months; 28-30 months; 31-33 months; 34-36 months; 37-42 months; 43-48 months; 49-60 months; 61-108 months; 109-144 months; 145-156 months; > 156 months.

\subsubsection{Across-country evaluation models}

\subsubsection{Across-country evaluation using raw data (AMACI model)}

Memory requirements, low convergence speed and CPU time prevented fitting a bivariate animal model considering each country's records as a different trait with a diagonal residual variance matrix across traits. Thus, a singletrait Animal Model accounting for Across-Country Interactions (AMACI) with fixed or genetic effects was fitted to the data and was mathematically equivalent to a bi-trait model [21]:

$$
\mathbf{y}=\mathbf{X b}+\mathbf{Z}_{\mathbf{d}} \mathbf{u}_{\mathbf{d}}+\mathbf{Z}_{\mathbf{m}} \mathbf{u}_{\mathbf{m}}+\mathbf{W}_{\mathbf{m}} \mathbf{e}_{\mathbf{m}}+\mathbf{e}
$$


where $\mathbf{y}$ is the vector of performance ordered by country $\mathbf{y}^{\prime}=\left(\mathbf{y}_{1}, \mathbf{y}_{\mathbf{2}}{ }^{\prime}\right), \mathbf{b}$ contains the $\mathrm{CG}$ and month effects within country and the interaction terms between country and age of the dam.

This AMACI model includes the relationship matrix across animals and dams (2 generation pedigree), with heterogeneous residual and maternal permanent environment variances across countries. In order to test the heterogeneity of genetic and residual variances across countries, and to estimate genetic correlations, a heteroskedastic model was used where $\operatorname{Var}(\mathbf{e})=\underset{\mathbf{i}=\mathbf{1}}{\oplus} \mathbf{I}_{\mathbf{n i}} \sigma_{\text {ei }}^{2}$, $\operatorname{Var}\left(\mathbf{e}_{\mathbf{m}}\right)=\underset{\mathbf{i}=\mathbf{1}}{\oplus} \mathbf{I}_{\mathbf{n i}} \sigma_{\mathrm{e}_{\mathrm{mi}}}^{2}, \mathrm{n}_{\mathrm{i}}$ being the number of records in the $i$ th country and $\operatorname{Var}(\mathbf{u})=\mathbf{G}_{\mathbf{C}} \otimes \mathbf{A}$, where $\mathbf{u}^{\prime}$ is the transposed vector of direct and maternal genetic effects in each of the two countries $\left(\mathbf{u}_{\mathbf{d} 1}, \mathbf{u}_{\mathbf{m} 1}, \mathbf{u}_{\mathbf{d} 2}, \mathbf{u}_{\mathbf{m} 2}\right)$, $\mathbf{A}$ is the relationship matrix between animals and dams and $\mathbf{G}_{\mathbf{C}}$ is the genetic variance matrix across countries.

$$
\mathbf{G}_{\mathbf{C}}=\left[\begin{array}{llll}
\sigma_{\mathrm{d}_{1}}^{2} & \sigma_{\mathrm{d}_{1} \mathrm{~m}_{1}} & \sigma_{\mathrm{d}_{1} \mathrm{~d}_{2}} & \sigma_{\mathrm{d}_{1} \mathrm{~m}_{2}} \\
\sigma_{\mathrm{d}_{1} \mathrm{~m}_{1}} & \sigma_{\mathrm{m}_{1}}^{2} & \sigma_{\mathrm{d}_{2} \mathrm{~m}_{1}} & \sigma_{\mathrm{m}_{1} \mathrm{~m}_{2}} \\
\sigma_{\mathrm{d}_{1} \mathrm{~d}_{2}} & \sigma_{\mathrm{d}_{2} \mathrm{~m}_{1}} & \sigma_{\mathrm{d}_{2}}^{2} & \sigma_{\mathrm{d}_{2} \mathrm{~m}_{2}} \\
\sigma_{\mathrm{d}_{1} \mathrm{~m}_{2}} & \sigma_{\mathrm{m}_{1} \mathrm{~m}_{2}} & \sigma_{\mathrm{d}_{2} \mathrm{~m}_{2}} & \sigma_{\mathrm{m}_{2}}^{2}
\end{array}\right] .
$$

As shown in recent study [19], the heteroskedastic model was highly significant when compared to a model with homogeneous (co)variances.

\subsubsection{Across-country evaluation using pre-corrected data (PAMAC model)}

An animal model with across-country interactions was applied to the vector of performance $\mathbf{y}$ corrected for all the estimated fixed effects $\mathbf{b}_{\mathbf{e}}(\mathrm{CG}$, age of dam... ) under within-country evaluations.

$$
\mathbf{y}-\mathbf{X} \mathbf{b}_{\mathbf{e}}=\mathbf{K v}+\mathbf{Z}_{\mathbf{d}} \mathbf{u}_{\mathbf{d}}+\mathbf{Z}_{\mathbf{m}} \mathbf{u}_{\mathbf{m}}+\mathbf{W}_{\mathbf{m}} \mathbf{e}_{\mathbf{m}}+\mathbf{e}
$$

where $\boldsymbol{v}$ is the vector of fixed country means.

The same structures of (co)variances were considered as for the AMACI model.

\subsubsection{Multiple-trait across-country evaluation (MACE model)}

MACE was the model initially proposed by Schaeffer [22] for international evaluation of dairy sires, where traits corresponded to de-regressed national 
EBV of bulls considered as correlated traits in the different countries. The current procedure used to de-regress national sire proofs is described by Jairath et al. [9]. This method makes the observations independent of genetic group effects and relationships among animals (to avoid double counting), as well as accounting for accuracy of national proofs by considering weights based on the information used to derive national EBV.

In order to use the INTERBULL de-regression program without any modification, some genetic groups have to be defined for MACE, although all previous evaluations were run without any grouping of unknown parents. For French records, three genetic groups were defined: unknown sires, unknown maternal grandsires and unknown maternal granddams. For Trans-Tasman records, seven genetic groups were defined: two groups for unknown sires (French or non-French origin); the same two groups for unknown MGS; and three groups for maternal granddams (unknown, Aus/NZ, or French origin). Each of these groups contained at least 40 animals. The same grouping strategy was considered for the de-regression and for MACE evaluation.

Only a selected sample of bulls with enough information could be used from the dataset described in Table III for variance component estimation by MACE on de-regressed proofs. This sample included bulls born between 1986 and 1995 with at least five progeny and five maternal grandprogeny recorded for WW. It contained 642 bulls in France and 266 in Australia / New Zealand, of which seven bulls were link sires.

Two MACE were run separately for de-regressed direct and maternal proofs. Although the theory has been proposed [24] to run a single MACE model with direct and maternal effects, it has not yet been applied to real data and no software was therefore available. The weights used to de-regress proofs were the number of sire progeny for direct proofs, and the number of daughters' progeny (maternal grand progeny) for maternal proofs. In this dataset, the average number of progeny (maternal grandprogeny) was 60 (51) for a French sire and 32 (23) for a Trans-Tasman sire. Two other weighting methods [10,25] were previously studied [18] on this dataset. The MTEDC method [10], which is the standard method used in international evaluation of dairy sires for calving ease, produced estimates of genetic variances and correlations across countries that were very sensitive to the sampling of bulls (number of cohorts, minimum information requirement). The MTEDC method had been developed for dairy sires, whose progeny and grandprogeny numbers are higher than for beef sires and spread more across herds. The MTEDC method probably underestimated the reliabilities for beef sires, because it did not account for the sire's own performance or the dams' progeny performance for dams without their own 
WW record. In the subsequent sections, only MACE results based on progeny numbers are therefore presented.

\subsection{Software}

ASREML [6] was used for estimation of variance components and the evaluations based on an animal model. Two main programs were necessary to run the MACE sire evaluation:

1) the INTERBULL de-regression program was used to de-regress the proofs within country;

2) the MACE program was used to estimate variance components and EBV for the across-country evaluation.

This last program was an AI-REML algorithm initially written by Ignacy Misztal and modified by Tom Druet (INRA-SGQA, personal communication) to weigh each observation.

\section{RESULTS AND DISCUSSION}

\subsection{Estimation of genetic parameters}

\subsubsection{Within-country evaluation (AMWC model)}

The estimates of within-country genetic parameters are reported in Table IV. In the French herds sampled in this study, the estimate of direct genetic variance is about $60 \%$ larger than the Trans-Tasman estimate, while the estimates of maternal permanent environmental and maternal genetic variance are similar across countries. The larger direct genetic variance in France may be explained by the fact that French calves are able to better express their growth potential, since the environment during the first few months of life is under greater control. Another explanation may be a greater emphasis on selection for growth of Trans-Tasman sires, therefore reducing the direct genetic variance. In France, calves are born in the winter and stay with their dam in a shed for their first 3 months before going to pasture, while dams and calves in Australia or New Zealand stay on pasture throughout the year without any supplementary feed given most of the time. This difference in the cow-calf management may also be the source of the different estimates of the genetic correlation between direct and maternal effects, which was more negative in the French population than in the Trans-Tasman one. 
Table IV. Estimates of genetic parameters* within-country (SE).

\begin{tabular}{ccccccc}
\hline & $h_{d}^{2}$ & $h_{m}^{2}$ & $R_{d m}$ & $c^{2}$ & $\sigma_{\mathrm{e}}^{2}$ & $\sigma_{\mathrm{p}}^{2}$ \\
\hline France & $0.31(0.02)$ & $0.10(0.01)$ & $-0.21(0.06)$ & $0.10(0.01)$ & 305 & 582 \\
AUS / NZ & $0.22(0.03)$ & $0.13(0.02)$ & $-0.10(0.12)$ & $0.13(0.02)$ & 278 & 509 \\
\hline
\end{tabular}

${ }^{*} h_{d}^{2}, h_{m}^{2}, R_{d m}$ are the direct heritability, the maternal heritability and the direct-maternal genetic correlation, respectively. $C^{2}$ is the proportion of phenotypic variance $\sigma_{\mathrm{p}}^{2}$ due to maternal permanent environmental effects, and $\sigma_{\mathrm{e}}^{2}$ is the residual variance.

French genetic parameter estimates were consistent with those estimated for a larger dataset using a sire-MGS-dam within MGS model [17], except for the variance due to the maternal permanent environment $\left(c^{2}\right)$ which was estimated at only $5 \%$ of the phenotypic variance instead of $10 \%$ in the present study. The use of a sire-MGS-dam model instead of an animal-dam model might have underestimated $c^{2}$ in the larger sample, leading to the discrepancy between the two studies. The similarity of genetic parameter estimates between both studies is a strong argument to believe that no selection bias was induced by the sampling of French herds. Trans-Tasman estimates were similar to parameters used in BREEDPLAN for Limousin cattle, which include the direct-maternal genetic correlation set to null, and 0.23 and 0.11 for direct and maternal heritabilities, respectively [14].

\subsubsection{Across-country evaluation using raw data (AMACI model)}

Because of the lack of information to estimate the correlation between maternal effects across countries, it was necessary to force the genetic matrix to be positive definite in the estimation procedure, making it impossible to get standard errors for the estimates. The estimated genetic parameters under the AMACI model are reported in Table V. As already observed in the withincountry analyses, the residual and direct genetic variances were higher in the French data. The estimate of the correlation between direct genetic effects across countries was 0.86 , while the estimate of the correlation between maternal genetic effects across countries was 0.80. Applying Meyer and Hill's [16] method for approximating the standard errors of direct and maternal genetic correlation estimates gave standard errors of 0.25 and 0.50 , respectively.

The genetic correlation estimates are in the range of previous estimates either on Angus cattle across Australia and New Zealand [15], on Charolais cattle across Ireland, France and the United Kingdom [19] and across Australia, New Zealand and North America [4], or on Hereford cattle across 
Table V. Estimates of genetic parameters under across-country models using raw (AMACI model) and pre-corrected (PAMAC model) data.

\begin{tabular}{lcccc}
\hline & \multicolumn{2}{c}{ AMACI model } & \multicolumn{2}{c}{ PAMAC model } \\
\hline Parameter $^{\mathrm{a}, \mathrm{b}}$ & France & AUS / NZ & France & AUS / NZ \\
\hline$\sigma_{\mathrm{p}}^{2}$ & 583 & 510 & 506 & 406 \\
$\sigma_{\mathrm{e}}^{2}$ & 306 & 279 & 270 & 227 \\
$h_{d}^{2}$ & 0.31 & 0.22 & $0.26(0.01)$ & $0.14(0.02)$ \\
$h_{m}^{2}$ & 0.10 & 0.13 & $0.09(0.01)$ & $0.12(0.02)$ \\
$c^{2}$ & 0.10 & 0.13 & $0.13(0.01)$ & $0.16(0.01)$ \\
$R_{d m}$ & -0.21 & -0.12 & $-0.05(0.06)$ & $0.15(0.11)$ \\
\hline$R d_{F r} d_{T r}$ & & 0.86 & $0.76(0.22)$ \\
$R m_{F r} m_{T r}$ & & 0.80 & $0.51(0.93)$ \\
$R d_{F r} m_{T r}$ & & 0.19 & $0.42(0.57)$ \\
$R m_{F r} d_{T r}$ & \multicolumn{2}{c}{-0.25} & $0.23(0.45)$ \\
\hline
\end{tabular}

${ }^{a}$ Phenotypic $\left(\sigma_{\mathrm{p}}^{2}\right)$ and residual $\left(\sigma_{\mathrm{e}}^{2}\right)$ variances; direct $\left(h_{d}^{2}\right)$ and maternal $\left(h_{m}^{2}\right)$ heritabilities; maternal permanent environmental variance as proportion of phenotypic variance $\left(c^{2}\right)$; directmaternal genetic correlation $\left(R_{d m}\right)$.

b Direct $\left(R d_{F r} d_{T r}\right)$ and maternal $\left(R m_{F R} m_{T r}\right)$ genetic correlations across countries; directmaternal genetic correlations across countries $\left(R d_{F r} m_{T r} ; R d_{T r} m_{F r}\right)$.

North America, Uruguay and Argentina [3,11]. With across-country estimates over 0.80 either for direct or maternal effects on weaning weight in this study, and in previous studies, there is little evidence for any significant genotype by country interactions that will re-rank animals for their WW breeding values across temperate environments in the world. However, strong evidence of heterogeneity of genetic and environmental variances was found in this study, as in most of the previous studies. If no significant genotype by country interaction exists, a single-trait model across countries is appropriate to predict direct breeding values. For weaning weight, maternal breeding values are also predicted by the model and the appropriateness of a single-trait model depends on the homogeneity of direct-maternal correlations within and across countries [18]. Due to the heterogeneity of these correlations, a multi-trait analysis was recommended [18] to allow a correct ranking within and across countries of animals on their maternal breeding values.

\subsubsection{Across-country evaluation using pre-corrected data (the PAMAC model)}

Variance component estimates obtained using PAMAC model are reported in Table $\mathrm{V}$, along with estimates from the AMACI model. The maternal 
permanent environmental variances were similar to the AMACI model estimates; $64 \mathrm{~kg}^{2}$ for both countries under the PAMAC model; 62 and $66 \mathrm{~kg}^{2}$ for France and Australia / New Zealand, respectively, under the AMACI model. However, residual and genetic (co)variance component estimates under the PAMAC model were smaller than their corresponding estimates under the AMACI model.

The explanation for the lower variance component estimates using precorrected data (PAMAC model) was the strong increase in degrees of freedom to estimate REML residual variances on pre-corrected data rather than on raw data. The number of CG effects (12 451) to estimate from 83389 records greatly reduced the number of degrees of freedom to estimate the residual variances on raw data. This explanation was validated by using an AMACI model (i.e. fitting all fixed effects) on pre-corrected data: estimates of all fixed effects were obviously very close to zero and (co)variance component estimates were similar to those estimated with raw data. Because the heritabilities and the genetic correlations within and across countries are modified by the precorrection step when dealing with large numbers of contemporary groups, using pre-corrected data (PAMAC model) cannot be recommended to estimate genetic parameters for beef cattle populations across countries.

\subsubsection{Multiple-trait across-country evaluation (MACE model)}

Table VI presents the parameters estimated using the MACE approach. The direct and maternal genetic correlation estimates between de-regressed proofs were much smaller (about 0.50) than the estimates obtained using raw data, possibly because MACE does not account for all information in the dam proofs and pedigree. As was the case for PAMAC model estimates, the non-estimation of CG effects under a MACE model may have also reduced the covariances across countries.

The INTERBULL program (used to de-regress the proofs within country) proposed, as a by-product, an estimate of sire variance within country for a given heritability of the trait. In this study, these sire variance estimates were quite different from the estimates obtained from the across-country evaluation by the MACE program. Deriving sire variances from within country ASREML analyses proved that the MACE estimates were correct. In consequence, the heritabilities that were estimated from the bulls' de-regressed proofs are very different from the heritabilities assumed in the de-regression step. Initially, these assumed heritabilities were the parameters obtained using raw data (Tab. IV). However, due to the inconsistency observed between the 
Table VI. Across-country MACE parameters ${ }^{\mathrm{a}}$.

\begin{tabular}{lcc}
\hline & France & AUS / NZ \\
\hline$V_{d}\left(V_{r}\right)$ & $35.0(241.2)$ & $20.8(118.3)$ \\
$V_{m}\left(V_{r}\right)$ & $7.8(250.5)$ & $10.2(237.7)$ \\
\hline$R d_{F r} d_{T r}(\mathrm{SE})$ & \multicolumn{2}{c}{$0.45(0.23)$} \\
$R m_{F r} m_{T r}(\mathrm{SE})$ & \multicolumn{2}{c}{$0.49(0.62)$} \\
\hline
\end{tabular}

${ }^{\text {a }}$ Sire variances for direct $\left(V_{d}\right)$ and maternal $\left(V_{m}\right)$ de-regressed proofs; residual variance of the corresponding de-regressed proofs $\left(V_{r}\right)$; correlations between France and Australia for direct $\left(R d_{F r} d_{T r}\right)$ and maternal $\left(R m_{F r} m_{T r}\right)$ genetic effects.

estimates of sire variance from the de-regression and the MACE programs, "corrected" heritabilities were used (Appendix). They lead to more consistent results, especially for maternal proofs. Using this approach accounts for the fact that direct proofs should not be de-regressed for the random maternal permanent environment and maternal genetic effects (and vice-versa for maternal proofs), because direct and maternal de-regressed proofs are evaluated separately by MACE. Liu et al. [12] proposed this approach for deriving the direct and maternal weights.

\subsection{Comparison of national and international evaluations}

\subsubsection{Animal model evaluations}

When running separate national (within-country) evaluations, there were 28180 animals (844 sires) evaluated within Australia / New Zealand and 92130 animals (1571 sires) evaluated within France. In across-country evaluations, there were 121277 animals (2402 sires). Correlations between EBV predicted under a national evaluation (AMWC model) and by an across-country evaluation using raw data (AMACI model) were greater than 0.99 for both direct and maternal effects for all animals (Tab. VII). Hence, in a given country, the animals were rank in the same manner under both evaluations. However, there was some re-ranking observed for sires $(r \sim 0.93-0.95)$, especially for link sires $(r \sim 0.62-0.96)$. In particular, the ranking of link sires in Australia / New Zealand was impacted by the addition of French information: the correlation between Trans-Tasman within-country EBV and those predicted under the AMACI model was 0.86 (0.62) for direct (maternal) effects.

Two sets of results are reported in Table VII for EBV predicted using precorrected performance data (PAMAC model). The first set $(P)$ of results refer to $\mathrm{EBV}$ predicted using genetic parameters estimated under the same PAMAC 
Table VII. Correlations between EBV predicted within $(W)$ and across countries using models AMACI $(A)$ and PAMAC $\left(P, P^{*}\right)^{\mathrm{a}}$.

\begin{tabular}{lcccccc}
\hline & \multicolumn{3}{c}{ Direct EBV } & \multicolumn{3}{c}{ Maternal EBV } \\
\hline & All & All & Common & All & All & Common \\
& Animals & Sires & Sires & Animals & Sires & Sires \\
\hline$W_{F r} A_{F r}$ & 1.00 & 0.95 & $0.93(\mathrm{a})$ & 1.00 & 0.94 & $0.96(\mathrm{a})$ \\
$W_{T r} A_{T r}$ & 0.99 & 0.95 & $0.86(\mathrm{~b})$ & 0.99 & 0.93 & $0.62(\mathrm{~b})$ \\
$A_{F r} A_{T r}$ & 0.99 & 0.98 & $0.98(\mathrm{c})$ & 0.88 & 0.85 & $0.82(\mathrm{c})$ \\
& & & & & & \\
$W_{F r} P_{F r}$ & 1.00 & 0.95 & $0.93(\mathrm{a})$ & 0.98 & 0.91 & $0.86(\mathrm{a})$ \\
$W_{T r} P_{T r}$ & 0.99 & 0.94 & $0.86(\mathrm{~b})$ & 0.97 & 0.90 & $0.56(\mathrm{~b})$ \\
$P_{F r} P_{T r}$ & 0.97 & 0.96 & $0.95(\mathrm{c})$ & 0.78 & 0.69 & $0.68(\mathrm{c})$ \\
& & & & & & \\
$W_{F r} P_{F r}^{*}$ & 1.00 & 0.95 & $0.93(\mathrm{a})$ & 1.00 & 0.94 & $0.96(\mathrm{a})$ \\
$W_{T r} P_{T r}^{*}$ & 0.99 & 0.95 & $0.88(\mathrm{~b})$ & 0.99 & 0.93 & $0.60(\mathrm{~b})$ \\
$B_{F r} P_{T r}^{*}$ & 0.99 & 0.98 & $0.97(\mathrm{c})$ & 0.87 & 0.85 & $0.79(\mathrm{c})$ \\
& & & & & & \\
$A_{F r} P_{F r}^{*}$ & 1.00 & 1.00 & $1.00(\mathrm{c})$ & 0.95 & 0.91 & $0.91(\mathrm{c})$ \\
$A_{T r} P_{T r}$ & 0.97 & 0.97 & $0.99(\mathrm{c})$ & 0.95 & 0.92 & $0.96(\mathrm{c})$ \\
$A_{F r} P_{F r}^{*}$ & 1.00 & 1.00 & $1.00(\mathrm{c})$ & 1.00 & 1.00 & $1.00(\mathrm{c})$ \\
$A_{T r} P_{T r}^{*}$ & 1.00 & 1.00 & $1.00(\mathrm{c})$ & 1.00 & 1.00 & $1.00(\mathrm{c})$ \\
\hline
\end{tabular}

${ }^{a}$ Across-country evaluation using raw data $(A)$; across-country evaluation on pre-corrected data $(P)$; across-country evaluation on pre-corrected data using variance component estimates obtained under the AMACI model $\left(P^{*}\right)$.

(a) Link sires having progeny in both countries $(n=13)$.

(b) Australian sires identified in the French pedigree $(n=18)$.

(c) Identified French males $(n=28)$.

model, while the second set $\left(P^{*}\right)$ refers to EBV predicted using genetic parameters estimated under an AMACI model.

High correlations with within-country evaluations were observed for both sets of PAMAC models for direct EBV, similar to those obtained in the comparison between national and AMACI EBV. PAMAC maternal EBV for set P differed slightly from AMACI maternal EBV for sires $(r \sim 0.91)$, and they were also less correlated with their corresponding within-country maternal EBV. This re-ranking of animals was due to differences in within-country genetic parameters (Tab. V).

Direct and maternal EBV for set $P^{*}$ were very similar to their corresponding EBVs predicted under an AMACI model (Tab. VII), even for the common sires across countries. Therefore, the prediction of breeding values was not affected by the separate estimation of $\mathrm{CG}$ effects within country in set $P^{*}$ compared to 
the across-country joint estimation of CG in the AMACI model. There may be several reasons why the preferred model (an across-country evaluation using raw data; AMACI model) cannot be run, including computational issues (too memory and time consuming) or political issues (no raw data published). In these circumstances, an across-country evaluation using pre-corrected data (PAMAC model) seems to be an excellent alternative, at least if it can be run using estimates of genetic and phenotypic parameters derived under an AMACI model. This approach was not compared to MACE results in the next section, because the results were very similar to those from the AMACI model.

\subsubsection{International sire comparison}

The main benefit of a joint evaluation is the increased availability of superior seed stock provided by the comparability of EBV between foreign and domestic bulls, and therefore, the bulls in the top 100 are of primary interest in international evaluations.

Table VIII presents the correlations between national and international EBV for the sires born between 1986 and 1995 evaluated with all across-country models $(n=901)$. The three international EBV (predicted using Models AMACI, PAMAC and MACE) were highly correlated with their corresponding national EBV for both direct $(>0.99)$ and maternal $(>0.97)$ effects for these sires. However, re-ranking was observed for some top bulls. The choice of the top 100 of sires across countries would be different depending on the implemented model (Tab. IX) and on the selection criterion (direct or maternal EBV), although only a few link sires (0 to 4$)$ are in the top 100. The EBV predicted under the MACE model favour within-country sire selection when compared to other models. This is most likely because correlations between French and Trans-Tasman MACE EBV are lower $(\sim 0.80)$ than those observed for other models. For example, correlations between French and Australian EBV under the AMACI model are over 0.90 (Tab. VIII), leading to greater sire selection across countries (Tab. IX). The results for set $P$ of EBV predicted under a PAMAC model (Tab. IX) were intermediate for the origin of top sires across countries.

\section{IMPLICATIONS}

An animal model on raw performance, accounting for heterogeneous variances and different genetic correlations between countries, was the model of 
Table VIII. Correlations between within (W) and across-country EBV predicted by Models AMACI (A), PAMAC (P) and MACE (M) for sires born between 1986 and $1995^{\mathrm{a}}$.

\begin{tabular}{lcc}
\hline & Direct EBV & Maternal EBV \\
\hline$W_{F r} A_{F r}$ & 1.00 & 1.00 \\
$W_{T r} A_{T r}$ & 0.99 & 0.97 \\
$A_{F r} A_{T r}$ & 0.98 & 0.90 \\
$W_{F r} P_{F r}$ & 1.00 & 0.98 \\
$W_{T r} P_{T r}$ & 0.99 & 0.97 \\
$P_{F r} P_{T r}$ & 0.97 & 0.78 \\
$W_{F r} M_{F r}$ & 1.00 & 1.00 \\
$W_{T r} M_{T r}$ & 0.99 & 1.00 \\
$M_{F r} M_{T r}$ & 0.78 & 0.81 \\
\hline
\end{tabular}

${ }^{a}$ Across-country evaluation using raw data (AMACI model); across-country evaluation on precorrected data (PAMAC model); MACE (MACE model).

Table IX. Number of sires born in France (link sires in brackets) in the top 100 of French or Trans-Tasman sires ranked on EBV predicted by the three different international evaluation models.

\begin{tabular}{lcccc}
\hline & \multicolumn{2}{c}{ Direct EBV } & \multicolumn{2}{c}{ Maternal EBV } \\
\cline { 2 - 5 } $\begin{array}{l}\text { International } \\
\text { strategy }\end{array}$ & $\begin{array}{c}\text { French } \\
\text { Top 100 }\end{array}$ & $\begin{array}{c}\text { Trans-Tasman } \\
\text { Top 100 }\end{array}$ & $\begin{array}{c}\text { French } \\
\text { Top 100 }\end{array}$ & $\begin{array}{c}\text { Trans-Tasman } \\
\text { Top 100 }\end{array}$ \\
\hline AMACI model & $77(4)$ & $70(4)$ & $77(1)$ & $66(1)$ \\
PAMAC model & $77(4)$ & $61(4)$ & $86(1)$ & $55(2)$ \\
MACE model & $99(4)$ & $43(3)$ & $94(1)$ & $41(1)$ \\
\hline
\end{tabular}

choice for an international genetic evaluation in order to get the best consistency between national and international ranking of animals and the best estimates of genetic parameters across countries. The preferred model allows for the prediction of international EBV for all animals: sires, dams and calves. Feasibility to handle all herds in three countries had been proved [20] on a dataset with over 1.6 millions of records. However, if this model cannot be implemented either for political reasons or computational reasons, running an animal model with across country interactions on pre-corrected data (for all national fixed effects) may be a satisfying solution for beef cattle populations, at least when using the variance components estimated previously on a subset of raw data. The MACE approach may be a sufficient alternative to compare sires across countries for beef cattle populations with sufficient genetic links to get good estimates of genetic correlations across countries. However, the low 
connectedness across countries may not allow the MACE approach in many beef cattle populations.

\section{ACKNOWLEDGEMENTS}

The authors would like to thank Z. Liu, T. Mark, S. Minery and B. Tier for providing part of the MACE programs and for helping in the understanding of the results. They also thank the Irish Cattle Breeding Federation, the Meat and Livestock Commission, the Institut de l'Élevage and INTERBULL subcommittee of ICAR for financing this research, and the Australian and French Limousin societies for providing the data.

\section{REFERENCES}

[1] Banos G., Schaeffer L.R., Burnside E.B., North American genetic evaluation of Ayrshire bulls with a linear model, 4th World Congr. Genet. Appl. Livest. Prod. 14 (1990) 62.

[2] Canavesi F., Boichard D., Ducrocq V., Gengler N., De Jong G., Liu Z., Production traits European joint evaluation (PROTEJE), Interbull Bull. 27 (2001) 32-34.

[3] De Mattos D., Bertrand J.K., Misztal I., Investigation of genotype $\times$ environment interactions for weaning weight for Hereford in three countries, J. Anim. Sci. 78 (2000) 2121-2126.

[4] Donoghue K., Bertrand J.K., Investigation of genotype by country interactions for growth traits for Charolais populations in Australia, Canada, New Zealand and USA, Livest. Prod. Sci. 85 (2004) 129-137.

[5] Fikse F., Banos G., Weighting factors in international genetic evaluations: effects on international breeding value and reliability estimates, Interbull Bull. 22 (1999) 1-6.

[6] Gilmour A.R., Cullis B.R., Welham S.J., Thompson R., ASREML Reference Manual (2000).

[7] Goddard M.E., A method for comparing sires evaluated in different countries, Livest. Prod. Sci. 13 (1985) 321-331.

[8] International Dairy Federation, IDF recommended procedure for international comparison of genetic merit of dairy cattle, International Dairy Federation (1981) A-Doc 64.

[9] Jairath L., Dekkers J.C.M., Schaeffer L.R., Liu Z., Burnside E.B., Kolstad B., Genetic evaluation for herd life in Canada, J. Dairy Sci. 81 (1998) 550-562.

[10] Jakobsen J.H., Fikse W.F., Liu Z., Sullivan P., Outline of a procedure to calculate weighting factors for models with maternal effects, Interbull Bull. 31 (2003) $65-69$.

[11] Lee D.H., Bertrand J.K., Investigation of genotype $\times$ country interactions for growth traits in beef cattle, J. Anim. Sci. 80 (2002) 330-337. 
[12] Liu Z., Pasman E., Reinhardt F., Reents R., Application of the multiple trait effective daughter contribution to a linear model with direct and maternal genetic effects for calving traits, Interbull Bull. 30 (2003) 75-81.

[13] Mattalia S., Bonaiti B., Use of full sib families to estimate the coefficients of conversion formulas between countries, Interbull Bull. 8 (1993) 73-74.

[14] McDonald A., Understanding the 2003 Limousin sire summary, in: Australian and New Zealand Limousin 2003 sire summary (2003), The Australian Limousin Breeders Society Ltd. and the Limousin Beef Breeders Society of New Zealand, $10 \mathrm{p}$.

[15] Meyer K., Estimates of genetic parameters and breeding values for New Zealand and Australian Angus cattle, Aust. J. Agric. Res. 46 (1995) 1219-1229.

[16] Meyer K., Hill W.G., Approximation of sampling variances and confidence intervals for maximum likelihood estimates of variance components, J. Anim. Breed. Genet. 109 (1992) 264-280.

[17] Phocas F., Laloë D., Genetic parameters for birth and weaning traits in French specialized beef cattle breeds, Livest. Prod. Sci. 89 (2004) 121-128.

[18] Phocas F., Donoghue K., Graser H.U., Comparison of alternative strategies for an international genetic evaluation of beef cattle breeds, Interbull Bull. 32 (2004) $18-24$.

[19] Quintanilla R., Laloë D., Renand G., Heterogeneity of variances across regions for weaning weight in charolais breed, in: 7th World Congr. Genet. Appl. Livest. Prod., 19-23 août 2002, Montpellier, France (2002) CD-ROM communication $\mathrm{n}^{\circ} 18-10$.

[20] Renand G, Laloë D., Quintanilla R., Fouilloux M.N., A first attempt of an international genetic evaluation of beef breeds in Europe, Interbull Bull. 31 (2003) $151-155$.

[21] Robert C., Foulley J.L., Ducrocq V., Genetic variation of traits measured in several environments. I. Estimation and testing of homogeneous genetic and intraclass correlations between environments, Genet. Sel. Evol. 27 (1995) 111-123.

[22] Schaeffer L.R., Multiple-trait across country evaluation of dairy sires, Interbull Bull. 8 (1993) 21.

[23] Schaeffer L.R., Multiple-country comparison of sires, J. Dairy Sci. 77 (1994) 2671-2678.

[24] Schaeffer L.R., Multiple trait international bull comparisons, Livest. Prod. Sci. (2001) 145-153.

[25] Tier B., Meyer K., Approximating prediction error covariances among additive genetic effects within animals in multiple-trait and random regression models, J. Anim. Breed. Genet. 121 (2004) 77-89.

[26] Weigel K.A., Rekaya R., Clustering herds across country borders for international genetic evaluation, Interbull Bull. 22 (1999) 31-37.

[27] Wilmink J.B.M., Meijering A., Engel B., Conversion of breeding values for foreign populations, Livest. Prod. Sci. 14 (1986) 223-229. 


\section{APPENDIX: CORRECTED HERITABILITIES FOR THE PROOF DE-REGRESSION WHEN RUNNING SEPARATE MACE FOR DIRECT AND MATERNAL EBV}

The reliability $\mathrm{R}_{x}$ of a sire index $\mathrm{x}$ (d: direct EBV, m: maternal EBV) based on its $\mathrm{n}_{x}$ progeny is derived by the well known formula of selection index theory: $R_{x}=n_{x} /\left(n_{x}+k_{x}\right)$, where

$$
k_{x}=\left(\sigma_{\mathrm{e}}^{2}+0.75 * \sigma_{\mathrm{x}}^{2}\right) /\left(0.25 * \sigma_{x}^{2}\right) .
$$

After approximating $R_{x}$, an effective progeny number is then calculated by Liu et al. [12] as:

$$
n_{x}=k_{x}^{*} R_{x} /\left(1-R_{x}\right) .
$$

For a single trait model with the only prediction of direct genetic values,

$$
k_{x}=\left(4-h_{x}^{2}\right) / h_{x}^{2} .
$$

But for a trait with maternal effects, the permanent environment and maternal genetic variances, as well as the correlation ( $\mathrm{rg}$ ) between direct and maternal effects must be accounted for in the derivation of the weights $\mathrm{n}_{x}$ to be used in the proof de-regression step, because the contribution by correlated genetic effects will not be considered in separate MACE evaluations of direct and maternal proofs.

The phenotypic variance is calculated as: $\sigma_{\mathrm{p}}^{2}=\sigma_{\mathrm{d}}^{2}+\sigma_{\mathrm{m}}^{2}+\sigma_{\mathrm{dm}}+\sigma_{\mathrm{em}}^{2}+\sigma_{\mathrm{e}}^{2}$. Therefore equation (1) can be rewritten as:

$$
k_{x}=\left(4-h_{x}^{2}\right) / h_{x}^{2}-\left(4 / h_{x}^{2}\right) *\left(h_{y}^{2}+c^{2}+r g^{*} h_{d *} h_{m}\right),
$$

with $y=m$ when $x=d$ and $y=d$ when $x=m$.

Consequently for $r g>-\left(h_{y}+c 2 / h_{y}\right) / h_{x}, k_{x}$ derived by equation (3) is smaller than the corresponding value derived by equation (2) for a single trait model. An equivalent heritability under a single trait model can be derived for direct or maternal effects to be de-regressed by rewriting (2) as:

$$
h_{x}^{2}=4 /\left(1+k_{x}\right)
$$

where $k_{x}$ is derived by equation (3).

Applying formula (4) to our Limousin case gave the following corrected heritabilities to use in the de-regression step:

\begin{tabular}{lcccc}
\hline & \multicolumn{2}{c}{ France } & \multicolumn{2}{c}{ AUS / NZ } \\
\hline & $h_{d}^{2}$ & $h_{m}^{2}$ & $h_{d}^{2}$ & $h_{m}^{2}$ \\
\hline Initial heritability & 0.31 & 0.10 & 0.22 & 0.13 \\
Corrected heritability & 0.37 & 0.16 & 0.29 & 0.19 \\
\hline
\end{tabular}

